\title{
Multi-actor approaches to implement cooperative strategies and value chains based on sustainability
}

\author{
Caterina Contini ${ }^{1}$, Giuseppe Marotta ${ }^{2}$ and Biancamaria Torquati ${ }^{3^{*}}$
}

\author{
*Correspondence: bianca.torquati@ \\ unipg.it \\ ${ }^{3}$ Department of Agricultural, Food \\ and Environmental Sciences, \\ University of Perugia, Borgo XX \\ giugno, 74, 06121 Perugia, Italy \\ Full list of author information is \\ available at the end of the article
}

\begin{abstract}
This special issue of Agricultural and Food Economics consists of four articles that were part of the scientific programme of the First SIDEA-SIEA Joint Conference, held in Bisceglie in September 2017. The conference afforded agricultural economists the opportunity to reflect on cooperative strategies to promote competitiveness of the agri-food supply chain, with a focus on environmental quality and social sustainability. The selected articles address these themes from different perspectives: those of firms, of consumers, and of policy makers, stressing that sustainability calls for the active participation of all of the actors. The case studies presented propose an effective interpretation of the strategies for value creation with respect to the challenges of climate change, food waste management, the development of marginal rural areas, and that of the fish sector.
\end{abstract}

\section{Background}

Over the last decade, the agri-food system has been facing several issues that affect the entire supply chain. Some of these are macroeconomic, such as those related to price volatility and market globalisation; others are mostly determined by the multi-faceted structure of the system, characterised by many producers and few wholesalers and retailers. The consequences of these issues are the homologation of products and standards, as well as the emergence of asymmetries along the supply chain in terms of information and bargaining power. The efficiency of the system is also undermined by the current food consumption model in which (i) food waste is booming, becoming a global emergency; (ii) public health is often threatened by new food scandals; and (iii) the environment is constantly endangered and natural resources (e.g. soil and water) are depleted indiscriminately (Nazzaro and Marotta 2016; Marotta et al. 2017).

To address these issues, agri-food companies are boosting their competitiveness by sharing their values and skills. In other words, all the actors involved in the supply chain are cooperating by instating different forms of governance and organisation. On the one hand, the agri-food system has seen the growth of cooperatives of producers, or of wholesalers and retailers (i.e. horizontal integration) in view of optimising companies' resources. On the other hand, the actors involved in the supply chain choose to internalise different stages of production (i.e. vertical integration) to pursue both economies of scale and a greater control of the production process. Lastly, mixed forms of

(c) The Author(s). 2020 Open Access This article is distributed under the terms of the Creative Commons Attribution 4.0 International License (http://creativecommons.org/licenses/by/4.0/), which permits unrestricted use, distribution, and reproduction in any medium, provided you give appropriate credit to the original author(s) and the source, provide a link to the Creative Commons license, and indicate if changes were made. 
organisation are emerging, in which producers or consumers come together to pursue common goals (e.g. consortia and buying groups, respectively). Through cooperation, the agri-food system has succeeded in reinventing itself by defining a new development process that focuses on sustainability-in all its dimensions-and on creating and communicating value, which does not stop at the single actor involved. These actions are instead distributed over the supply chain in order to promote the uniqueness of both territories and agri-food districts by enhancing environmental protection and social cohesion (Casini et al. 2012; Contini et al. 2006). It follows that a stable and resilient agri-food system, in the sense of its ability to address the issues highlighted, is a system that encourages all the actors involved to cooperate. In this sense, it is a system in which no one is left aside and the responsibilities of market failures are tackled instead of unloaded onto some actors of the chain, often the weaker ones (e.g. producers). A system designed in this way proves sustainable environmentally, economically, and socially.

\section{Report}

Cooperation, in all its forms, represents a valuable paradigm to define new horizons of development and build new organisational models of value creation according to a sustainable approach that concerns the entire supply chain (Contò et al. 2019).

In this framework, this special issue hosts four articles through which the Journal aims to offer several insights into the importance of promoting the development of an agri-food supply chain that is integrated and sustainable, and takes into consideration the needs of all the actors involved, whether producers or consumers.

Precisely, the authors investigate how to add value to the supply chain through the analysis of the consumption models (Canavari et al. 2019), certification schemes (Prosperi et al. 2019), evaluation methods for use in incentive schemes (De Menna et al. 2019), and forms of territorial cooperation (Scaramuzzi et al. 2019).

The role of consumers as co-responsible for environmental sustainability in agri-food production is addressed by Canavari et al. (2019) in the article entitled, "Consumer stated preferences for dairy products with carbon footprint labels in Italy". The paper discusses the current literature on consumers' willingness to pay for carbon footprint labels and presents two studies on consumer preferences with respect to greenhouse gas emissions certification. The findings contribute to improving the understanding of consumer behaviour. Precisely, they point out how consumer awareness of the environmental impact of food production and consumer trust in certification schemes can promote demand-driven sustainable productions.

The article by Prosperi et al. (2019) "Understanding fish labelling strategies to inform collective schemes for fisheries and aquaculture labels in Tuscany (Italy)" investigates the certification system of the fish catch in Tuscany using the convention theory. The results illustrate several forms of coordination that differ by final market and actors involved. The study offers insights for the implementation of labelling policies, highlighting how certification schemes are based on shared principles and quality conventions, the implementation of which benefits from previous collective experiences. Further, the authors point out the role of retailers in vertical coordination, showing that successful certifications are the results of well-rooted business-to-business relations.

The study by De Menna et al. (2019) entitled, "Combining life cycle assessment and costing for food waste prevention and valorisation" addresses a topic which has gained 
momentum over the past few years, namely food waste. Specifically, the study provides food waste practitioners with step-by-step guidance in assessing the environmental and social impacts of food waste by combining the Life Cycle Assessment (LCA) and the Life Cycle Costing (LCC) methodologies. The contribution of the study to the current debate is twofold: (i) it develops a consistent approach to assess-both in economic and in environmental terms-the impacts of the prevention of resource inefficiencies, novel valorisation options, and waste handling options relating to side flows in the food supply chain and (ii) the consistent approach developed in this study could be widely applied to measure value creation along the supply chains in the agri-food system.

Identifying trade-offs between environmental and economic aspects by implementing this approach could support the decision-making process of policy makers in designing supply chains that are more sustainable, both environmentally and economically.

Lastly, the article "Integrated supply-chain projects and multifunctional local development. The creation of a Perfume Valley in Tuscany" by Scaramuzzi et al. (2019) highlights that cooperation represents a source of added value and a strategic development tool also for territories.

The paper discusses how areas undergoing great pressure from the effects of globalisation, such as marginal rural areas, can implement Integrated Supply Chain Projects (Progetti Integrati di Filiera-PIF), which foster multifunctional development, focusing on innovation and on a new territorial identity. The authors emphasise the complexity of PIFs based on multi-measure tender notices, a multi-actor approach and the ensuing benefits: from enhancing the market access of agricultural producers to reducing the transaction costs related to the exchange of information and materials and from reducing the risk of opportunistic behaviour within the supply chain to increasing and multiplying the impact of single operations in support of the agricultural sector.

In order to analyse and improve the organisation and governance of the system, the authors use the Business Model Canvas (BMC) as a strategic tool that helps to define the organisation's business models according to a customer-oriented perspective. Previously, in agricultural economics studies, this tool had been used only to analyse and describe multifunctional farming models (Torquati et al. 2015; Pölling et al. 2017). The authors have also adopted a Participatory Action Research (PAR) approach in view of involving the local community in sharing and analysing their environment, on one hand, and identifying their strategic goals and planning their actions, on the other.

\section{Conclusions}

Taken as a whole, this collection of articles underlines the importance of the multiactor approach in attaining concrete results, as well as the necessity to identify and utilise tools capable of analysing the increasingly more complex challenges that agriculture faces. These tools, in turn, must be capable of producing results that can have major implications in agricultural policy.

The carbon footprint label is one of the most effective tools in helping fight climate changes, but it needs a reliable certification system capable of justifying the incentives given to farms, and to promote conscious purchase behaviours.

Voluntary labelling schemes are an opportunity for small- and medium-sized firms to implement competitive strategies, but they require clear procedures capable of 
activating equally clear policy guidelines on labelling and capable of promoting the coordination and cooperation of the actors involved in the value chain.

Integrated assessment methods, like the combination of Life Cycle Assessment (LCA) and Life Cycle Costing (LCC), are tools for planning production processes that are more sustainable from the environmental and economic viewpoint. They require results, however, that are comprehensible to and useable by those who intend to instate incentive actions to the advantage of producers (for example, public incentives or exchanges on the market of carbon credits).

The Progetti Integrati di Filiera (PIF) (Integrated Supply Chain Projects) are useful tools to define new strategies and plan innovative actions even in the most marginal rural areas. New tools of analysis are needed, however, like the Business Model Canvas (BMC), as well as participatory approaches (Participatory Action Research, PAR) in order to involve the local community in the phases of analysing and planning.

The four articles of this special issue provide a valid interpretation of the case studies analysed, the tools proposed, and the implications of agricultural policy suggested in response to the problems tied to climate change, marginal rural areas, the valorisation of food productions, and food waste by means of environmental certification.

\section{Authors' contributions}

CC participated in the coordination and the drafting of the report section; GM conceived of the study, and participated in the drafting of the background and report sections; BT participated in the design of the manuscript, and the drafting the report and conclusion sessions. All authors read and approved the final manuscript.

\section{Competing interests}

The authors declare that they have no competing interests.

\section{Author details}

${ }^{1}$ Department of Agriculture, Food, Environment and Forestry, University of Florence, P.le delle Cascine, 18, 50144 Florence, Italy. ${ }^{2}$ Department of Law, Economics, Management and Quantitative Methods, University of Sannio, Piazza Arechi II, 82100 Benevento, BN, Italy. ${ }^{3}$ Department of Agricultural, Food and Environmental Sciences, University of Perugia, Borgo XX giugno, 74, 06121 Perugia, Italy.

Published online: 31 January 2020

\section{References}

Canavari, M., Coderoni, S. Consumer stated preferences for dairy products with carbon footprint labels in Italy. Agric Econ 8, 4 (2020) https://doi.org/10.1186/s40100-019-0149-1

Casini L, Contini C, Romano C (2012) Paths to developing multifunctional agriculture: insights for rural development policies. Int J Agric Resour Gov Ecol 9(3-4):185-203

Contini C, Zorini LO, Polidori R (2006) Network analysis of farming and non-farming activities for sustainable development. In: Changing European farming systems for a better future New visions for rural areas, pp 111-115

Contò, F., Fiore, M., La Sala, P., and Sisto, R. (2019). Cooperative strategies and value creation in sustainable food supply chain. FrancoAngeli

De Menna, F., Davis, J., Östergren, K. et al. A combined framework for the life cycle assessment and costing of food waste prevention and valorization: an application to school canteens. Agric Econ 8, 2 (2020) https://doi.org/10.1186/s40100-019$0148-2$

Marotta G, Nazzaro C, Stanco M (2017) How the social responsibility creates value: models of innovation in Italian pasta industry. Int J Globalisation Small Bus 9(2-3):144-167

Nazzaro C, Marotta G (2016) The Common Agricultural Policy 2014-2020: scenarios for the European agricultural and rural systems. Agric Food Econ 4(1):16

Pölling B, Prados MJ, Torquati BM, Giacchè G, Recasens X, Paffarini C, Alafranca O, Lorleberg W (2017) Business models in urban farming: a comparative analysis of case studies from Spain, Italy and Germany. Moravian Geogr Rep 25(3):166-180

Prosperi P, Brunori G, Bartolini F, Vergamini D (2020) Exploring institutional arrangements for local fish product labelling in Tuscany (Italy): a convention theory perspective. Agric Food Econ https://doi.org/10.1186/s40100-020-0151-7

Scaramuzzi S, Belletti G, Biagioni P (2020) Integrated supply-chain projects and multifunctional local development. The creation of a Perfume Valley in Tuscan. Agric Food Econ https://doi.org/10.1186/s40100-019-0150-8

Torquati B, Tancini C, Paffarini C, Illuminati R (2015) Empirical survey on business models of kindergarten farms. Agric Food Econ 3(1):25

\section{Publisher's Note}

Springer Nature remains neutral with regard to jurisdictional claims in published maps and institutional affiliations. 